\section{Algæ in Sodium Phosphate Solutions.}

WHнLе working in chemical laboratories I have sten noticed a green colour in the sodium phosphate sottles which did not occur in any other bottle. On sxamination under the microscope this proves to be lue to the presence of unicellular green algæ, either singly or in chains. I should be glad if any biologist would give me any particulars of this plant, and the season why it prefers sodium phosphate bottles to, say, sodium nitrate.

School House, Sherborne.

ONE of the algæ which occurs in sodium phosphate bottles is apparently a Chlorella, possessing a prominent pyrenoid, cells $3-5 \mu$ in diameter, from each of which four daughter cells may arise. Mr. W. R. Trotter's reference to cells in chains suggests that he may be dealing with a different species, a Palmella or a palmelloid state, for example. The Chlorella rather resembles a starved form of $C$. pyrenoidosis Chick, but the latter was described as growing in sewage effluents, rich in available nitrogen. Nevertheless, Dr. Chick (Proc. Roy. Soc., 71, 458; 1903) found that it would grow in solutions containing only ammonium salts, potassium phosphate, and sodium carbonate, and its mineral requirements were thus very low. Algæ growing in sodium phosphate solutions must similarly be able to grow on mere traces of the essential mineral elements. It is of interest to note that Chlorella, according to Hopkins and Wann, is one of the few plants which can grow without calcium.

The presence of such plants in sodium phosphate solutions and their absence from solutions of other sodium salts is probably an extreme illustration of a general tendency among the smaller green algæ to prefer dilute culture solutions in which phosphates are abundant or in excess. Calcium salts, and particularly nitrates, on the other hand, favour the development of small diatoms. So far as is known, however, diatoms are never obtained in culture by inoculation from the air, although green algæ may at times be obtained from this source. The diatoms have usually a higher salt requirement also, which equally will prevent their growth in solutions nominally of one salt.

The University, Leeds.

W. H. Pearsall.

\section{Oils, Greases, and High Vacua.}

In the course of some work (which I hope shortly to publish) on the evaporative distillation of petroleum derivatives, I became aware of the possibility and advantages of using oil in place of mercury as working fluid in condensation pumps. I was distilling lubricating oil in an apparatus similar in principle to that used by Brönsted and Hevesy to separate the isotopes of mercury. The saturation pressure of the oil vapour could be deduced from the observed rate of distillation and the estimated molecular weight of the oil : in a particular case the saturation pressure was about one dyne $/ \mathrm{cm}^{2}$ at $118^{\circ} \mathrm{C}$., that is, about the same as the saturation pressure of mercury at room temperature. No decomposition could be detected. Clearly, if this oil could be heated until its vapour pressure was, say, $100 \mathrm{dynes} / \mathrm{cm}^{2}{ }^{2}$, without decomposition, it could be used as working fluid in a condensation pump and might be expected to give a performance, without artificial cooling, comparable with the performance of a mercury condensation pump with a cold trap $100^{\circ} \mathrm{C}$. below room temperature. I therefore prepared by fractionation a quantity of this oil and evacuated ionisation gauges (large and small thermionic valves), on oil condensation pumps. have been unable to measure the lower limit of pressure reached by these pumps. $10^{-3}$ dynes $/ \mathrm{cm} .{ }^{2}$ has been reached without ovening the glasswork: when the glass was ovened, the ionisation current could not be detected with the instruments available - the pressure probably did not exceed $10^{-4} \mathrm{dynes} / \mathrm{cm} .^{2}$.

Not all oils can be distilled to dryness in the evaporative still. Decomposition usually begins at $320-340^{\circ}$ C. I was able to prepare a grease with a vapour pressure of not exceeding 1 dyne $/ \mathrm{cm} .^{2}$ at $320^{\circ} \mathrm{C}$. (as deduced from distilling speed) : this grease was used to lubricate the ground joint between the ionisation gauge and the pump in the above experiments. Mr. J. D. Cockeroft, at the Cavendish Laboratory, found the vapour pressure of this grease to be less than $10^{-3}$ dynes $/ \mathrm{cm} .{ }^{2}$ at $70^{\circ} \mathrm{C}$. As was to be expected, it was too small to be detected by the evaporation method used. Joints made with this grease may in fact be employed freely, even at temperatures as high as $70^{\circ} \mathrm{C}$. (This substance is not a' 'grease' in the sense used by the oil technologist, i.e. it does not contain a soap, but is simply a petroleum jelly residue.)

It has been customary to regard with grave suspicion the introduction of oil or grease into systems in which high vacua are to be produced. This attitude represents a generalisation which must now be subject to many reservations.

Research Laboratories,

Metropolitan-Vickers Electrical Co., Trafford Park, Manchester.

\section{Rayleigh's ' Radium Clock.}

Two years ago a 'radium clock' was constructed for the Chicago Radium Institute similar to the original one described by Strutt (Phil. Mag., 1903). Three milligrams of radium sulphate, contained in a thin-walled glass tube, was used as the activating source. A platinum wire sealed into the tube made metallic connexion with the gold leaf support. The containing tube was of pyrex glass and was fitted with a ground joint at the top to allow the removal and adjustment of the parts. A carefully cleaned glass rod was sealed into the upper half of the ground joint which served as a support for the source and gold leaves and provided sufficient insulation for the operation of the clock. A chemical deposit of silver made the inner walls of the tube conducting, with the exception of a small opening left for observation. Due to this silver coating, the tube was not baked out but was exhausted with mercury diffusion pumps.

At the lowest attainable vacuum (less than $10^{-5} \mathrm{~mm}$. of mercury) the period of the clock was about 29 seconds, but after twenty-four hours would increase appreciably, due to the accumulation of gas from the walls of the tube. After several days' pumping the tube was sealed and set up under a bell jar. The ground joint at the top was carefully sealed with red sealingwax. After several days the period of the clock increased from 29 seconds to 43 seconds, indicating either a leak or a slow emission of gas from the walls of the tube. However, the period remained approximately constant at 43 seconds for several months and was assumed to be in equilibrium. Small changes in period were noted, apparently due to changes in room temperature.

No observations were made of the period of the clock for more than a year, when it was noted that the period had decreased and now has a value of 34 seconds. Since any leakage of air into the tube would increase the period of the clock, it was thought that perhaps some 'clean up' action due to the $\beta$ - and $\gamma$ rays was taking place within the tube. It scarcely seems possible that any changes in the gold leaves 